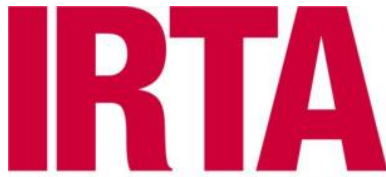

REEGERPA I TECONOLOGIA

AGROALIMENTAREIES

This is a pre-copyedited, author-produced version of an article accepted for publication in Journal of Economic Entomology following peer review. The version of record Bosch, Dolors, Marcela A Rodríguez, Laura Depalo, and Jesús Avilla. 2018. "Determination Of The Baseline Susceptibility Of European Populations Of Cydia Pomonella (Lepidoptera: Tortricidae) To Chlorantraniliprole And The Role Of Cytochrome P450 Monooxygenases".Journal Of Economic Entomology 111 (2): 844852. Oxford University Press (OUP). doi:10.1093/jee/toy020 is available online at: https://doi.org/10.1093//iee/toy020 


\section{Journal of Economic Entomology 10.1093/jee/toy020}

1 Determination of the baseline susceptibility of European populations of Cydia

2 pomonella (Lepidoptera: Tortricidae) to chlorantraniliprole and the role of

3 cytochrome $\mathbf{P 4 5 0}$ monooxygenases.

4 Dolors Bosch ${ }^{1}$, Marcela A. Rodríguez ${ }^{2}$, Laura Depalo ${ }^{3}$ and Jesús Avilla

$5 \quad{ }^{1}$ Institut de Recerca i Tecnologia Agroalimentàries (IRTA), Sustainable Plant Protection

6 Program, Avinguda Alcalde Rovira Roure, 191. 25198 Lleida, Spain.

$7 \quad 2$ Departamento de Zoología, Facultad de Ciencias Naturales y Oceanográficas,

8 Universidad de Concepción, Castilla 160-C, Concepción, Chile.

$9 \quad{ }^{3}$ DipSA (Department of Agricultural Science), Alma Mater Studiorum, University of

10 Bologna, Viale G. Fanin, 42. 40127 Bologna, Italy.

$11{ }^{4}$ Department of Crop and Forest Sciences, Agrotecnio, University of Lleida (UdL),

12 Avinguda Alcalde Rovira Roure, 191.25198 Lleida, Spain.

Short title: Baseline susceptibility of Cydia pomonella to chlorantraniliprole

Corresponding author: Dolors Bosch, IRTA Sustainable Plant Protection Program, Av.

17 Alcalde Rovira Roure, 191, 25198 Lleida (Spain). Tel. +34 973702633.

18 dolors.bosch@irta.cat 
21 The codling moth, Cydia pomonella, (L.) (Lepidoptera: Tortricidae) is the key pest on 22 pome fruit and walnut orchards worldwide. Its resistance to available insecticides has been widely reported. Chlorantraniliprole is an anthranilic diamide that was introduced in European countries in 2008-2009 and acts by activating the insect's ryanodine receptors.

The aims of this study were to determine the baseline susceptibility of European populations of $C$. pomonella to chlorantraniliprole, to establish the discriminant concentrations (DC) to check the possible development of resistance, and to know the role of cytochrome $\mathrm{P} 450$ monooxygenases (P450) in the possible susceptibility decrease of field populations to the insecticide.

Ten field populations from Spain along with others were used to calculate the baseline response of larvae to chlorantraniliprole incorporated into the diet. A pooled probit line was calculated and three DC were established: $0.3 \mathrm{mg}$ a.i. $/ \mathrm{kg}$ (close to the $\mathrm{LC} 50$ ), $1.0 \mathrm{mg}$ a.i./ $\mathrm{kg}$ (close to the $\mathrm{LC} 90$ ), and $10 \mathrm{mg}$ a.i./kg diets (three-fold the $\mathrm{LC}_{99}$ ). The $\mathrm{DC}$ were used to test the susceptibility of 27 field populations from France, Germany, Hungary, Italy and Spain. The corrected mortality observed in all cases ranged within the expected interval, even with Spanish populations that showed between $12.1 \%$ and $100.0 \%$ of individuals with high P450 activity. However, the mortality caused by the $\mathrm{DC}_{0.3}$ decreased as the mean P450 activity increased. Field populations resistant to other insecticides were susceptible to chlorantraniliprole. The determined baseline codling moth susceptibility is a valuable reference for tracking possible future alterations in the efficacy of the insecticide. 
The codling moth (CM), Cydia pomonella, (L.) (Lepidoptera: Tortricidae) is the key pest on pome fruit and walnut orchards in almost all the areas where these crops are cultivated. At present, its control is mostly achieved by a combination of pesticides and mating disruption (Witzgall et al., 2008; Ioriatti \& Lucchi 2016). The existence of CM insecticide-resistant populations is a widespread problem in many pome fruit production areas in the world, and it concerns 10 out of the 11 insecticide modes of action available to control this pest, depending on the country (IRAC Codling Moth WG, 2013), which are: $1 \mathrm{~A}$ - carbamates, $1 \mathrm{~B}$ - organophosphates, $3 \mathrm{~A}$ - pyrethroids, $4 \mathrm{~A}$ - neonicotinoids, 5 - spinosyns, 6 - avermectins, 7B - phenoxy-ethyl carbamates, 15 - benzoylureas, 18 diacylhydrazines and 22A oxadiazines (Sauphanor et al., 1998, 2000; Dunley and Welter, 2000; Reuveny \& Cohen, 2004; Fuentes-Contreras et al., 2007; Ioriatti et al., 2007; Stará \& Kocourek, 2007; Knight, 2010; Rodríguez et al., 2010, 2011, 2012; Voudouris et al., 2011; Grigg-McGuffin et al., 2015; Iscy and Ay, 2017). Codling moth resistance to insecticides is mainly metabolic, due to three enzymatic complexes (cytochrome P450 monooxygenases (P450), glutathione transferases (GST) and esterases (EST)) (www.irac-online.org), but mutations in the insecticide target site protein have also been detected (the acetylcholinesterase (AChE) mutation, only reported in the fruit growing area of Lleida (Spain) (Cassanelli et al., 2006), and the knockdown resistance ( $k d r)$ mutation (Brun-Barale et al., (2005)). For example, when compared to non-chemically treated orchards, an increase of the frequency of resistant codling moth individuals has been detected in many chemically treated orchards in the tree fruit area of Lleida, and enhanced P450 activity was the main enzymatic mechanism involved (Rodríguez et al., 2010, 2011; Bosch et al., 2016). However, enhanced GST and EST activity was also detected (Rodríguez et al., 2011), as the presence of AChE and $k d r$ mutations (Bosch et 
al., 2014). Metabolic cross-resistance is a big concern in any management resistance strategy, which may occur either at the level of interaction with the various chemical families or at a geographical level (Dunley and Welter, 2000; Reyes et al., 2007; Voudouris et al., 2011; IRAC Codling Moth WG, 2013). New pesticides with new modes of action and with an environmentally safe toxicological profile are then necessary to control resistant $\mathrm{CM}$ populations.

Chlorantraniliprole (Rynaxypyr®) and cyantraniliprole (Cyazypyr®), developed by DuPont (USA), are anthranilic diamides whose mode of action has been classified in the new insecticide group 28 (ryanodine receptor modulator) within the IRAC (Insecticide Resistance Action Committee) mode of action classification scheme (Nauen, 2006). By activating the insect ryanodine receptors (RyRs), they stimulate the release and depletion of intracellular calcium stores from the sarcoplasmic reticulum of muscle cells, causing impaired muscle regulation, paralysis and, ultimately, death (Cordova et al., 2006). Chlorantraniliprole acts primarily by ingestion and by contact on the larvae of chewing pests. Newly hatched larvae from treated eggs die when eating the chorion at emergence. It has extremely broad-spectrum effectiveness within the insect order Lepidoptera and some Coleoptera, Diptera and Isoptera, acting in a broad range of crops and showing very low mammalian toxicity and high selectivity to non-target arthropods (DuPont ${ }^{\mathrm{TM}}$, 2008; Lahm et al, 2009). Chlorantraniliprole is active on the codling moth, and it has been registered in European countries since 2008. Due to the potential of $C$. pomonella to develop resistance to insecticides, it is necessary to establish a baseline susceptibility database before or early after the introduction of a new insecticide to the market (Roditakis et al., 2013). The database has to include data from a wide geographical area, to know the natural variability of the response to the chemical in 
field populations, and it has to consider the state of the insecticide resistance in every area.

The aims of this study were to determine the baseline susceptibility of European codling moth populations to chlorantraniliprole, to establish the discriminant concentrations (DC), to check the possible development of resistance in the field, and to understand the possible role of $\mathrm{P} 450$ in the lack of susceptibility of field populations to this insecticide.

\section{Material and methods}

\section{Experimental protocol outline}

In our study, the concentration - response to chlorantraniliprole lines (mortality vs. concentration) by ingestion were first determined for eight Spanish field populations collected from 2007 to 2009 . These data along with others obtained from populations in Italy, France, Netherlands and Belgium and tested since 2005 in Italy were used by DuPont ${ }^{\circledR}$ to calculate the Discriminant Concentrations (DC). Values close to the $\mathrm{LC}_{50}$, $\mathrm{LC}_{90}$, and to three times the $\mathrm{LC}_{99}$ were chosen as the DC. These concentrations were then applied to 27 European populations collected from 2008 to 2015 to test their susceptibility. Two more concentration - response lines were later determined for two more Spanish populations collected in 2010. Their DC results were within the range of the ones calculated previously and all the probit line data were pooled to calculate a common probit line. Additionally, the probit line of chlorantraniliprole was also calculated for a Spanish susceptible strain (S-Spain) whose response to several insecticides is well known. Finally, the activity of P450 was measured for 12 field populations and for the laboratory susceptible strain. 
118 The list of the CM field populations used in the bioassays is shown in Table 1 . The 10 119 Spanish populations used to adjust probit lines were collected from 2007 to 2010 in the 120 Ebro Valley pome fruit production area (Catalonia and Aragon, NE of Spain) when the product was not registered. The 27 populations tested with the DC were collected from 2008 to 2015 in the pome fruit growing areas of France, Germany, Hungary, Italy, and Spain. They were collected before or after the registration of chlorantraniliprole, or from orchards that had not been sprayed with it.

125 Except in one case (Jun 3-63 (09), that was collected from an abandoned orchard), the 126 Spanish and most of the rest of the European field populations originated from commercial IPM orchards. The pest management strategy with chlorantraniliprole was the same in all countries, once the product was registered: only two applications per season on one single generation, preferable first generation. Most of the $\mathrm{CM}$ field populations were collected as diapausing larvae using corrugated cardboards installed in the field from July-August until October, but in some cases injured apples were collected or corrugated cardboards were installed in the field to obtain non diapausing larvae or both. When it was needed, the populations were reared until their second generation (F2) to have enough progeny to carry out the bioassays (Table 1).

The susceptible CM strain, S-Spain, was collected from an abandoned apple orchard in Lleida in 1992, and it has been reared since then using a semi-artificial dehydrated apple diet at the joint IRTA and UdL laboratory (Lleida, Spain). Its response to many insecticides, its P450, GST and EST enzymatic activity and the presence of the AChE mutation are well known (Rodríguez et al., 2010; Rodríguez et al., 2011; Bosch et al., 2014). 
141 The P450 activity in CM adults was determined for 12 field populations from the Ebro

142 Valley (Spain). Codling moth adults from the first flight were captured from seven orchards in pheromone traps in 2009 and 2010 (Table 1). As for the other five populations collected in 2010 and 2011, the P450 activity was measured on adults emerging from the collected diapausing larvae.

Insecticide and bioassays experimental procedure

Chlorantraniliprole was used as DPX-E2Y45 20SC (Coragen ${ }^{\circledR}$ 20SC, DuPont de Nemours France SAS, Nambsheim, France) and a Stonefly Premix ${ }^{\circledR}$ (Stonefly Industries LTD) lyophilized diet was used as feeding substrate in the bioassays, following the IRAC susceptibility test method 017 (www.irac-online.org) To complement the diet, CD International BA-128 multiwell plastic trays (each well of $15.9 \mathrm{~mm}$ diameter and 15.9 mm deep) and lids were used. Codling moth neonate larvae (less than 24-h old) were exposed to chlorantraniliprole in diet incorporated assays.

To calculate the baseline probit lines 20 grams of diet were mixed with $60 \mathrm{~g}$ of the insecticide solution at given concentrations ranging from 0.01 to $1.0 \mathrm{mg}$ a.i. $/ \mathrm{kg}$ of diet at approximately $3 \mathrm{x}$ series dilution. Given the results, a second series was performed to get a better fitting of the probit line. Distilled water was used as a solvent. Each well was filled with $0.5 \mathrm{~g}$ of treated diet, and the diet was pressed to be evenly distributed across the bottom. One neonate larvae per well was placed on the treated diet. At least three replications of 16 larvae were tested per each concentration. The trays were incubated at $22 \pm 1{ }^{\circ} \mathrm{C}, 16: 8 \mathrm{~h}(\mathrm{~L}: \mathrm{D})$ and $45 \%$ humidity. Larval mortality was assessed after four days. Larvae were considered dead when they did not move after a light touch with a brush or when they were moribund. Moribund larvae were those visibly affected and significantly different from normal ones; when they were probed and flipped on their back, the larva could not flip back right-side up, or, when it was able to do it, it did so with uncoordinated 
and slow movements. Only data in which control mortality was $<20 \%$ were analyzed. Missing larvae were subtracted from the initial number.

Once the DC were calculated, to test the susceptibility of 27 European field populations the same procedure was followed.

\section{P450 enzymatic activity}

The adult P450 activity was determined in the susceptible strain S-Spain and in 12 field populations (Table 1) with an in vivo protocol (Rodríguez et al. 2012) using 7-ethoxycoumarin-O-deethylation (ECOD) in a black microplate of 96 wells. The dissected abdomens of the adults were placed individually in a well containing $100 \mu \mathrm{L}$ of phosphate buffer (50 mM, pH 7.2) and 7-ethoxycoumarin (0.4 mM). After $4 \mathrm{~h}$ of incubation at 30 ${ }^{\circ} \mathrm{C}$, the reaction was stopped by adding $100 \mu \mathrm{L}$ of glycine buffer ( $\mathrm{pH} 10.4,10-4 \mathrm{M}$ ) with ethanol (v/v). Before the incubation, a minimum of $10 \%$ of the wells of each microplate were used as controls and received the glycine buffer to stop the reaction. The ECOD activity was measured by fluorescence with a $380 \mathrm{~nm}$ excitation filter and $465 \mathrm{~nm}$ emission filters and was expressed as pg of 7-ethoxycoumarin (7OH).insect ${ }^{-1} \cdot \mathrm{min}^{-1}$.

\section{Data analysis}

To calculate the baseline a probit analysis using the program POLO Plus (LeOra Software, 1987) was performed, and the $\mathrm{LC}_{50}$, the $\mathrm{LC}_{90}$ and their $95 \%$ fiducial limits were calculated. Two LC50 were considered significantly different when their fiducial limits did not overlap (Robertson et al. 2007). The resistant ratio (RR) relative to the most susceptible field population $\left(\mathrm{RR}-\mathrm{F}_{50}\right)$ and the resistance ratio relative to the susceptible laboratory strain (RR-L50) were calculated for the $\mathrm{LC}_{50}$. Values close to the $\mathrm{LC}_{50}$, to the LC 90 , and to three times the $\mathrm{LC}_{99}$ were chosen as the DC. The highest DC was expected to kill approximately $100 \%$ of larvae of the susceptible population, but a smaller percentage when applied to a resistant population (ffrench-Constant and Roush, 1990). 
191 To evaluate the susceptibility of the European field populations the corrected mortality

192 produced by the DC was calculated using Abbott's formula (Abbott, 1925), being the correction factor the mortality produced by the control treatment (water). The RR of each population for every DC was calculated by dividing the mortality of the most susceptible field population by the mortality produced in every field population strain $\left(\mathrm{RR}-\mathrm{F}_{0.3}, \mathrm{RR}-\right.$ $\mathrm{F}_{1.0}$ and RR-F 10.0$)$. Mean \pm SEM of the corrected mortality produced by the DCs and the coefficient of variation (CV) across all the field populations to evaluate the dispersion of the data were calculated.

The frequency of P450-resistant individuals in every CM field population analysed was compared to the susceptible S-Spain using a Pearson chi-square $\left(\chi^{2}\right)$ test. Moths were classified as resistant if their P450 enzyme activity exceeded the highest activity value corresponding to $90 \%$ of S-Spain individuals (Reyes et al., 2007). Regression lines between the mean $\mathrm{P} 450$ activity (pg $7 \mathrm{OH}$ insect ${ }^{-1} \mathrm{~min}^{-1}$ ) and the $\mathrm{LC}_{50}$, and between the P450 activity and the mortality produced by the $\mathrm{DC}_{0.3}$ for each population were calculated. Only the orchards with more than 20 adults analyzed were taken into account for the regression lines.

The results of the probit analysis and the RR are shown in Table 2. The $\mathrm{LC}_{50}$ values for the CM field populations ranged from 0.161 to $0.446 \mathrm{mg}$ a.i. $/ \mathrm{kg}$ diet. Some significant differences were found among the field populations, namely Torref 15-3 (SP) (08), Bal 2-480 (SP) (08) and SAS (SP) (09) were significantly less susceptible than five field populations, and Riud (SP) (10) was significantly more susceptible than four field populations. One population, Torreg 11-160 (SP) (08), showed no significant differences 
with any of the other field populations. Jun 3-63 (SP) (09), from an abandoned orchard, showed no significant differences with six of the ten tested field populations. The RR$\mathrm{F}_{50}$, calculated comparing each $\mathrm{LC}_{50}$ value with the $\mathrm{LC}_{50}$ value of the most susceptible field population (Riud (SP) 10, $0.161 \mathrm{mg}$ a.i./kg diet), ranged from 1.1 to 2.8.. The laboratory susceptible strain, S-Spain, was significantly more susceptible to chlorantraniliprole than any field population and it was not included in the calculation of the pooled LCs values. The RR-L50, calculated comparing each $\mathrm{LC}_{50}$ value with the $\mathrm{LC}_{50}$ value of the laboratory strain (S-Spain, $0.086 \mathrm{mg}$ a.i./kg diet) ranged from 1.9 to 5.2. SAS (SP) (09) had a high slope (4.860 \pm 0.557$)$ suggesting a more homogeneous response than the other populations and a narrow concentration range between the $\mathrm{LC}_{50}$ and $\mathrm{LC}_{90}$. The same happened with Riud (SP) (10), S-Spain and Tam (SP) (10) that had parallel slopes to SAS (SP) (09) $(\chi 2=3.34$, d.f. $=3, \mathrm{P}<0.343)$. Torreg 11-160 (SP) (08) had the lowest slope $(1.371 \pm 0.168)$ compared to the next smallest one, Torref $15-3$ (SP) (08) $(\chi 2=4.80$, d.f. $=1, \mathrm{P}<0.028)$. Due to its low slope Torreg 11-160 (SP) (08) had a very wide interval of concentrations between $\mathrm{LC}_{90}$ and $\mathrm{LC}_{50}$ and thus, had high intrapopulation variability and it did not present significant differences with any other field population. The $\mathrm{LC}_{90}$ values for the $\mathrm{CM}$ field populations ranged from 0.339 to $2.788 \mathrm{mg}$ a.i. $/ \mathrm{kg}$ diet.

The $\mathrm{LC}_{50}$ value of the pooled data was $0.250 \mathrm{mg}$ a.i./ $\mathrm{kg}$ of diet, the $\mathrm{LC}_{90}$ was $0.888 \mathrm{mg}$ a.i./ $\mathrm{kg}$ of diet and the $\mathrm{LC} 99$ was $3.323 \mathrm{mg}$ a.i./ $\mathrm{kg}$ of diet. These results are according to the DC selected to test the susceptibility of $\mathrm{CM}$ field populations to chlorantraniliprole: 0.3 and $1.0 \mathrm{mg}$ a.i. $/ \mathrm{kg}$ diets, approximately the $\mathrm{LC}_{50}$ and the $\mathrm{LC}_{90}$, respectively, and 10 $\mathrm{mg}$ a.i./kg diet which corresponded to three-fold the $\mathrm{LC}_{99}$ value of the pooled data probit line results.

Table 3 shows the corrected mortality and the resistance ratio relative to the most susceptible field population (RR-Fs) obtained with each DC for the European CM field 
populations. All the DC applied produced a $100 \%$ of mortality on the susceptible population S-Spain, as expected according to its probit line results (Table 2). Feeding the European field populations larvae with concentrations of $0.3,1.0$ and $10.0 \mathrm{mg}$ a.i. $/ \mathrm{kg}$ diet produced mean corrected mortalities of $70.82 \%, 96.44 \%$ and $99.85 \%$, respectively. The $\mathrm{CV}$ were low for $0.3 \mathrm{mg}$ a.i./kg diet (31.17), and very low for $1.0(7.21)$ and $10.0 \mathrm{mg}$ a.i./kg diets (0.52). The RR-F 0.3 ranged between 1.1 and 4.8, and between 1.0 and 1.5 for the other two DC.

The P450 enzymatic activity of CM adults and the relative frequency of resistant individuals (those whose $\mathrm{P} 450$ activity was higher than $23.92 \mathrm{pg} 7 \mathrm{OH}$ adult ${ }^{-1} \mathrm{~min}^{-1}$ ) are shown in Table 4. The mean P450 activity ranged from 10.52 to $74.61 \mathrm{pg}^{7} \mathrm{OH}$ insect $^{-1}$ $\min ^{-1}$, and the frequency of resistant individuals in the field populations ranged from $12.1 \%$ to $100.0 \%$ (populations Jun 3-63 (SP) (09) and Balaguer 2-480 (SP) (08) for both variables, respectively). The variance of the frequency of resistant insects is strongly explained by the $\mathrm{P} 450$ mean activity of the field populations $\left(\mathrm{R}^{2}=95.32\right)$, which implies that there are few individuals with a very high resistance level that strongly influence the mean P450 value (Figure 1). Although data were restricted to four field populations, the regression line between the frequency of resistant insects and the $\mathrm{LC}_{50}$ values showed a high coefficient of determination $\left(\mathrm{R}^{2}=89.77\right.$, Figure 2$)$. When the regression line was adjusted between the $\mathrm{P} 450$ mean activity and the mortality produced by the $\mathrm{DC}_{0.3}$, the coefficient of determination was lower than in the other cases, but it explained the $69.82 \%$ of the variance (Figure 3). The regression lines obtained with the higher DCs $(1.0 \mathrm{mg}$ a.i./kg of diet and $10.0 \mathrm{mg}$ a.i./kg of diet) hadn't good adjustments due to the high mortalities obtained in all the field populations treated. 
266 To determine the DC, populations collected before the registration of chlorantraniliprole

267 were used. The first European countries to get the product registered on pome fruits were Romania in 2008 and Italy in 2009, and in Spain the product was registered in 2011. The CM Spanish field populations showed a high and relatively uniform susceptibility to chlorantraniliprole. This is likely because of the RR relative to the most susceptible population $\left(R R-F_{50}\right)$ was lower than 2.8 , even though significant differences on the LC50s were observed among populations (Mota-Sanchez et al., 2002). All the field populations, even the abandoned orchard Jun 3-63 (SP) (09), were significantly less susceptible to chlorantraniliprole than the laboratory strain, S-Spain. FfrenchConstant and Roush (1990) stated that susceptible strains held for long periods in the laboratory may bear little resemblance to susceptible strains currently found in the field. Thus, it would be more useful to determine the appropriate DC on the basis of field strains before wide commercial introduction of the specific pesticide. Therefore, to establish a useful baseline to know the natural response variability to the insecticide in the field populations, the laboratory susceptible strain was not included in the pooled data to determine the DCs. Nevertheless, once the product is applied in the field, susceptibility of insect populations might reduce over time due to potential resistance evolution (ffrench-Constant and Roush, 1990). In this case, susceptible strains can be helpful as an invariable mortality reference point, which are commonly used (Zheng et al., 2011; Lai et al., 2011; da Silva, 2012; Caballero et al., 2013). $\mathrm{mg}$ a.i./kg of diet (Torref 15-3 (SP) (08)), and are equivalent to $0.110 \mathrm{mg}$ a.i./L and 0.59 $\mathrm{mg}$ a.i./L, respectively. The same insecticide diet incorporation bioassay obtained an 
(Lai et al., 2011) and $0.28 \mathrm{mg}$ a.i./L in Choristoneura rosaceana (Harris) (Lepidoptera:

Tortricidae) (Sial and Brunner, 2012). Different species respond in a different way to the same insecticide, independently of the body mass differences. For example, CM is heavier than Lobesia botrana (Denis \& Schiffermüller) (Lepidoptera: Tortricidae) but females of CM were 115 times more susceptible to thiacloprid than females of $L$. botrana were (Navarro et al., 2017). In the laboratory, where the larval feeding behavior is conditioned, these different responses are mainly due to that different species may have different metabolic procedures or detoxification methods (Rodríguez et al., 2012). The highest resistance ratio relative to the laboratory strain of S-Spain (RR-L50) was 5.2 (Table 2) which is a low value compared to the highest value observed for Chinese $S$. exigua field populations (17.1, Lai et al., 2011) in which chlorantraniliprole was either briefly introduced or, in some cases, never used against. As found our study, narrow variations in the $\mathrm{LC}_{50}$ values were also found in some other Lepidoptera species: Tuta absoluta (Meyrick) (Lepidoptera: Gelechiidae) (Campos et al., 2015), Plutella xylostella (Linnaeus) (Lepidoptera: Plutellidae) (Wang et al., 2010) or Cnaphalocrocis medinalis (Güenée) (Lepidoptera: Pyralidae) (Zheng et al., 2011).

The mortality caused by the $\mathrm{DC}_{0.3}$ (concentration close to the $\mathrm{LC}_{50}$ of the pooled field population) on European field populations also showed a low variability among populations, with a mean mortality of $70.82 \%$, and a CV equal to 31.17 (Table 3). The RR-F 0.3 obtained were similar to the RR-F50, demonstrating its reliability in comparing populations. The $\mathrm{DC}_{1.0}$ produced a mean mortality of $96.44 \%$, and all the mortalities were higher than $85.3 \%$ except in the French population, Isle SLS (FR) (13), where it was 67.7\%. The highest DC tested, $10 \mathrm{mg}$ a.i./kg of diet, caused $100.0 \%$ mortality in all the field populations except in Isle SLS (FR) (13) and Malpartit (SP) (09), suggesting the 
presence of a small proportion of resistant individuals in these two populations, but generally supporting the lack of resistance to chlorantraniliprole in the field. Malpartit (SP) (09) was collected before the introduction of the product in the marked but the populations had a very high mean P450 activity (Table 4), what can play a role in the detoxification of the active ingredient, as is discussed later. Eleven European field populations were collected after registration of the product, from 2012 onwards, and these populations proved as susceptible as the previously tested Spanish populations. Some of them were collected over more than a year, as in: Le Thor (two years), Isle SLS (three years) and Noves P (five consecutive years). The mortality obtained with Isle SLS with the DC of $0.3 \mathrm{mg}$ a.i. $/ \mathrm{kg}$ of diet decreased over the years from $89.1 \%$ in 2009 to $38.1 \%$ in 2013. This population was from a location with very high pest pressure and where trials with Rynaxypyr were done over several years, so, the loss of efficacy of the product may be due to the presence of resistant individuals in the population. Nevertheless, the field population, Noves, showed a similar level of mortality for all the years, ranging between $69.6 \%$ to $93.3 \%$, except in 2012 , when the efficacy of the $\mathrm{DC}_{0.3}$ decrease to $20.8 \%$ (obtaining a $\mathrm{RR}_{0.3}$ of 4.8 ). In these field populations, the $\mathrm{DC}_{1.0}$ and $\mathrm{DC}_{10.0}$ reached $100.0 \%$ of mortality suggesting an error in the assay or an unexplained variation in the mortality obtained, something that can occur in unexposed field populations (Sawicki, 1987) and demonstrating the utility of using more than one DC.

Widespread resistance of CM field populations from the Ebro Valley area (NE of Spain) has been demonstrated, mainly to azynphos-methyl and other OP, lambda-cyhalothrin and methoxyfenozide, among other active ingredients (Rodríguez et al., 2010;

Rodríguez et al., 2011). Insecticide bioassays (Bosch et al., 2017) were done with some of the Spanish field populations tested with chlorantraniliprole. Compared with the susceptible population S-Spain, PuigverdB (11) was resistant to the pyretroid lambda- 
cyhalothrin $(\mathrm{RR}=15.4)$, and PuigverdC $(11)$ was resistant to lambda-cyhalothrin $(\mathrm{RR}=$ 872.0), methoxyfenozide $(\mathrm{RR}=14.6)$ and thiacloprid $(\mathrm{RR}=11.2)$, besides being tolerant $(2<\mathrm{RR}<10)$ to other active ingredients such as chlorpyrifos-ethyl and spinetoram. Tam (10) was susceptible to all the tested active ingredients, and SAS (11) and Le Thor (12) were tolerant to different active ingredients but with RRs always lower than 4.4. None of these populations were resistant to chlorantraniliprole, with SAS (11) the only one that had a RR slightly higher than $2(R R=2.2)$. Despite being multi-resistant populations, PuigverdB (11) and PuigverdC (11) responded to the DCs of chlorantraniliprole with high mortalities, at the same or a higher level than the rest of the tested populations (Table 3). These results showed the absence of cross-resistance among chlorantraniliprole and lambda-cyhalothrin, methoxyfenozide and thiacloprid in these field populations suggesting that the resistant mechanisms involved do not affect the proper activity of the product. This lack of cross-resistance was also found in $P$. xylostella field and laboratory selected populations (Wang et al., 2010), Spodoptera litura (Fabricius) (Lepidoptera: Tortricidae) (Sang et al., 2016) and with cyantraniliprole, another anthranilic diamide, in selected resistant populations of Bemisia tabaci (Gennadius) (Hemiptera: Aleyrodidae) (Grávalos et al., 2015). Therefore, a high correlation between the two anthranilic diamides was found in $T$. absoluta (Campos et al., 2015) and in S. litura (Sang et al., 2016); and with flubendiamide, a phthalic diamide, in P. xylostella although this active ingredient had never been used (Wang et al., 2013). Chlorantraniliprole is the only diamide currently registered for pest control in pome fruits, but formulated products of cyantraniliprole are under development to control a cross-spectrum of chewing and sucking pests from the insect orders Hemiptera, Lepidoptera and Coleoptera (Selvy et al., 2013). They have obtained promising results in the control of aphid pests with no evidence of cross- 
resistance with other aphid insecticides (Foster et al., 2012). In the case of using both active ingredients in the same crop to control different pests, an intensive check to detect an increase in the resistance levels would be necessary due to the possible crossresistance between IRAC Group 28 products, together with an accurate resistance management strategy combining its use.

With reference to enzymatic detoxification mechanisms, synergism assays in S. litura (Su et al., 2012), S. exigua (Lai et al., 2011) and P. xylostella (Wang et al., 2010) demonstrated that P450, EST and GST were not the main mechanisms involved in chlorantraniliprole resistance and neither were they involved in the cyantraniliprole resistance of S. litura in China (Sang et al., 2016). However, in T. absoluta, Campos et al. (2015) found a moderate correlation between the cytochrome-P450-monooxygenases activity (P450) and a susceptibility to chlorantraniliprole and cyantraniliprole. Sial et al. (2011) found that EST could be involved in the detoxification of chlorantraniliprole in a resistant selected laboratory population of C. rosaceana; and Cao et al. (2010) found that there was an increase of EST and GST activity in chlorantraniliprole treated insects of Helicoverpa armigera (Hübner) (Lepidoptera: Noctuidae). The main enzymatic mechanism for insecticide detoxification of the Spanish CM field populations is P450 (Rodríguez et al., 2010; Rodríguez et al., 2011), and in the studied populations, the frequency of P450 resistant insects present in the field explained the $69.72 \%$ of the mortality obtained with the lower chlorantraniliprole DC ( $0.3 \mathrm{mg}$ a.i./ $\mathrm{kg}$ of diet). The coefficient of determination was higher when the $\mathrm{LC}_{50}$ was used instead of the mortality of the $\mathrm{DC}_{0.3}\left(\mathrm{R}^{2}=89.77\right)$; however, we considered that five points (the laboratory and four field populations) to adjust a regression line are too few to draw any conclusion. Despite these results, due to the high efficacy of the product in the tested field 
populations, $\mathrm{P} 450$ seems not to be the main mechanism implied in the detoxification of the product although it may have a certain role in it.

C. pomonella is a key fruit pest that has extensively demonstrated its ability to develop resistance to most of the registered insecticides. Chlorantraniliprole, a new reduced risk insecticide that can control a wide range of lepidopteran pests, has proved its high efficacy in European field populations by obtaining low RR and variability when the LC were calculated and DC tested. The efficacy of the product in this assay not only has shown the natural variability in the response concentration-mortality in a broad geographical area, but also the lack of cross-resistance of the product with other commonly used insecticides in Spanish field populations, such as lambda-cyhalothrin, methoxyfenozide or thiacloprid. Nevertheless, it seems there is a relationship between the frequency of resistant individuals due to high P450 enzymatic activity and the mortality produced by the approximate $\mathrm{LC}_{50}$ used as a DC. As many insecticides can induce an P450 enzymatic activity increase, the use of a strict resistance management strategy would be necessary to maintain the efficacy of the product for a long time (http://www.irac-online.org). In fact, this strategy has been considered from the beginning by DuPont which recommend a restricted number of applications per season product.

\section{Acknowledgments}

412 The authors would like to express their sincere thanks to the fruit growers and to the grower advisors of the different areas (ADV technicians) who helped identify the best 
orchards for the assay, to the collectors of the field populations in the different countries and to Mònica Pérez for her technical help. Special thanks to J. L. Rison, M. O. Haxaire and S. Pasquini, from DuPont, for their helpful comments on the manuscript. This study was funded by DuPont and partially supported by grants AGL2013-49164 and AGL201677373 of the Spanish Ministry for Science and Innovation and by the CERCA Programme / Generalitat de Catalunya.

\section{References}

Abbott, W. S. 1925. A method for computing the effectiveness of an insecticide. J. Econ. Entomol. 18:265-267.

Bosch, D., J. Avilla, and M. A. Rodríguez. 2014. Occurrence of target-site mutations and PSMO enzymatic detoxification in adults of codling moth, Cydia pomonella (L.), from Spanish field populations. Book of Abstracts of the Joint Meeting of the sub-Groups "Pome fruit arthropods" and "Stone fruits" Vienna (Austria) 6th - 9th October.

Bosch, D., J. Avilla, and M. A. Rodríguez. 2016. Captures of P450-resistant Cydia pomonella adults as affected by lure, crop management system and flight. Bull. Entomol. Res. 106:54-62.

Bosch, D., J. Avilla, and M. A. Rodríguez. 2017. Monitoring resistance of Cydia pomonella (L.) Spanish field populations to new chemical insecticides and the mechanisms involved. Pest Manage. Sci. DOI: 10.1002/ps.4791. 
Involvement of a sodium channel mutation in pyrethroid resistance in Cydia pomonella

Caballero, R., S. Cyman, and D. J. Schuster. 2013. Baseline Susceptibility of Bemisia tabaci, Biotype B (Hemiptera: Aleyrodidae) to Chlorantraniliprole in Southern Florida. Fla. Entomol. 96:1002-1008.

445 to ryanodine receptor modulators. Pest Manage. Sci. 71:537-544.

449 Helicoverpa armigera. Pestic. Biochem. Physiol. 98:99-103. Cydia pomonella (L.). Insect Biochem. Mol. Biol. 36:642-653.

457 
da Silva, J. E., H. A. A. de Siqueira, T. B. M. Silva, M. R. de Campos, and R.

465

466

467

468

469

470

471

472

473

474

475

476

477

478

479

480

481

482

483

484

485

Barros. 2012. Baseline susceptibility to chlorantraniliprole of Brazilian populations of Plutella xylostella. Crop Prot. 35:97-101.

Dunley, J. E. and S. C. Welter. 2000. Correlated insecticide cross-resistance in azinphosmethyl resistant codling moth (Lepidoptera: Tortricidae). J. Econ. Entomol. 93:955-962.

DuPont $^{\text {TM }}$. 2008. Coragen ${ }^{\circledR}$. Insect control. Technical Bulletin. E.I. du Pont de Nemours, Puteaux, France.

ffrench-Constant, R. H., and R. T. Roush. 1990. Resistance detection and documentation: the relative roles of pesticidal and biochemical assays, pp. 4-38. In R. T. Roush and B. E. Tabashnik (eds.), Pesticide Resistance in Arthropods. Chapman and Hall, New York, NY.

Foster, S. P., I. Denholm, J-L. Rison, H. E. Portillo, J. Margaritopoulis, and R.

Slater. 2012. Susceptibility of standard clones and European field populations of the green peach aphid, Myzus persicae, and the cotton aphid, Aphis gossypii (Hemiptera: Aphididae), to the novel anthranilic diamide insecticide cyantraniliprole. Pest Manage. Sci. 68:629-633. 

of azinphos-methyl resistance and activity of detoxifying enzymes in codling moth (Lepidoptera: Tortricidae) from central Chile. J. Econ. Entomol. 100:551-556.

489

Grávalos, C., E. Fernández, A. Belando, I. Moreno, C. Ros, and P. Bielza. 2015.

Cross-resistance and baseline susceptibility of Mediterranean strains of Bemisia tabaci to cyantraniliprole. Pest Manage. Sci. 71:1030-1036.

493

494

495

496

497 selection of insecticides. Pest Manage. Sci. 71:234-242.

498

499

500

501 methods and mechanisms. J. Appl. Entomol. 131:453-459.

502

503

504

Ioriatti, C., and Lucchi, A. 2016. Semiochemical strategies for tortricid moth control in apple orchards and vineyards in Italy. J. Chem. Ecol. 42(7): 571-583

505

506

507

508

Iscy, M., and R. Ay. 2017. Determination of resistance and resistance mechanisms to thiacloprid in Cydia pomonella (L.) (Lepidoptera: Tortricidae) populations collected from apple orchards in Isparta Province, Turkey. Crop Prot. 91:82-88. 
IRAC Codling Moth WG. 2013. Insecticide Resistance Action Committee, IRAC

Mode of Action Classification, v.6.3, IRAC Mode of Action Working Group, (2009)

Knight, A. L. 2010. Cross-resistance between azinphos-methyl and acetamiprid in populations of codling moth, Cydia pomonella (L.) (Lepidoptera: Tortricidae), from Washington State. Pest Manage. Sci. 66:865-874.

517

Lahm, G. P., D. Cordova, and J. D. Barry. 2009. New and selective ryanodine receptor activators for insect control. Bioorg. Med. Chem. 17:4127-4133. Software, Berkeley, CA.

523

Lai, T., J. Li, and J. Su. 2011. Monitoring of beet armyworm Spodoptera exigua (Lepidoptera: Noctuidae) resistance to chlorantraniliprole in China. Pestic. Biochem. Physiol. 101:198-205.

527

Mota-Sanchez, D., S. P. Bills, and M. E. Whalon. 2002. Arthropod resistance to pesticides: Status and overview, pp. 241-272. In: W. Wheeler and B. Gainesville (eds.), Pesticides in agriculture and the environment. Marcel Decker, New York, NY.

Nauen, R. 2006. Insecticide mode of action: return of the ryanodine receptor. Pest. 
536 effect of three neurotoxic insecticides with different modes of action on adult males and

537 females of three tortricid moth pests. J. Econ. Entomol. doi: 10.1093/jee/tox113.

538

539 Reuveny, H., and E. Cohen. 2004. Evaluation of mechanisms of azinphos-methyl

540 resistance in codling moth Cydia pomonella (L.). Arch. Insect Biochem. Physiol. 57:

$54192-100$.

542

543

Reyes, M., P. Franck, J. P. Charmillot, C. Ioriatti, J. Olivares, E. Pasqualini, and B.

544

Sauphanor. 2007. Diversity of insecticide resistance mechanisms and spectrum in

European populations of the codling moth, Cydia pomonella. Pest Manag. Sci. 63:890902.

547

548

Robertson, J. L., N. E. Savin, R. M. Russell, and H. K. Preisler. 2007. Bioassays with 549 Arthropods, 2nd Ed. CRC Press. Boca Raton, USA.

550

551

Roditakis, E., C. Skarmoutsou and M. Staurakaki. 2013. Toxicity of insecticides to 552 populations of tomato borer Tuta absoluta (Meyrick) from Greece. Pest Manag. Sci. 69: 834-840.

Rodríguez, M.A., D. Bosch, B. Sauphanor, and J. Avilla. 2010. Susceptibility to organophosphate insecticides and activity of detoxifying enzymes in Spanish populations of Cydia pomonella (L.) (Lepidoptera: Tortricidae). J. Econ. Entomol. 103: 482-491. 
Rodríguez, M. A., D. Bosch, and J. Avilla. 2011. Assessment of insecticide resistance in

561

562

563

564

565

566

567

568

569

570

571

572

573

574

575

576

577

578

579

580

581

582

583

eggs and neonate larvae of Cydia pomonella (Lepidoptera: Tortricidae). Pestic. Biochem. Physiol. 100:151-159.

Rodríguez, M. A., D. Bosch, and J. Avilla. 2012. Azinphos-methyl and carbaryl resistance in adults of the codling moth (Cydia pomonella (L.), Lepidoptera: Tortricidae) from Northeastern Spain. Pestic. Biochem. Physiol. 103:43-48.

Sawicki, R. M. 1987. Definition, detection and documentation of insecticide resistance, pp. 105-117. In M. G. Ford, D. W. Holloman, B. P. S. Khambay, and R. M. Sawiki (eds.), Combating resistance to xenobiotics; biological and chemical approaches. Ellis Horwood, Chichester, England.

Sang, S., B. Shu, X. Yi, J. Liu, M. Hu, and G. Zhong. 2016. Cross-resistance and baseline susceptibility of Spodoptera litura (Fabricius) (Lepidoptera: Noctuidae) to cyantraniliprole in the south of China. Pest Manage. Sci. 72:922-928.

Sauphanor, B., V. Brosse, C. Monier, and J. C. Bouvier. 1998. Differencial ovicidal and larvicidal resistance to benzoylureas in the codling moth, Cydia pomonella. Entomol. Exp. Appl. 88:247-253.

Sauphanor, B., V. Brosse, J. C. Bouvier, P. Speich, A. Micoud, and C. Martinet. 2000. Monitoring resistance to diflubenzuron and deltametrin in French codling moth populations (Cydia pomonella). Pest Manage. Sci. 56: 74-82. 
603

Selvy, T. P., G. P. Lahm, T. M. Stevenson, K. A. Hughes, D. Cordova, B. Annan, J. D. Barry, E. A. Benner, M. J. Currie, and T. F. Pahutski. 2013. Discovery of cyantraniliprole, a potent and selective anthranilic diamide ryanodine receptor activator with cross-spectrum insecticidal activity. Bioorg. Med. Chem. Lett. 23:6341-6345.

Stará, J., and F. Kocourek. 2007. Insecticidal resistance and cross-resistance in populations of Cydia pomonella (Lepidoptera: Tortricidae) in Central Europe. J. Econ. Entomol. 100:1587-1595.

Sial, A. A., J. F. Brunner, and S. F. Garczynski. 2011. Biochemical characterization of chlorantraniliprole and spinetoram resistance in laboratory selected obliquebanded leafroller, Choristoneura rosaceana (Harris) (Lepidoptera: Tortricidae). Pestic. Biochem. Physiol. 99:274-279.

Sial, A. A., and J. F. Brunner. 2012. Selection for resistance, reversion towards susceptibility and synergism of chlorantraniliprole and spinetoram in obliquebanded leafroller, Choristoneura rosaceana (Lepidoptera: Tortricidae). Pest Manage. Sci. $68: 462-468$.

Su, J., T. Lai, and J. Li. 2012. Susceptibility of field populations of Spodoptera litura (Fabricius) (Lepidoptera: Noctuidae) in China to chlorantraniliprole and the activities of detoxification enzymes. Crop Prot. 42:217-222.

Voudouris, C. C., B. Sauphanor, P. Franck, M. Reyes, Z. Mamuris, J. A. Tsitsipis, J. Vontas, and J. T. Margaritopoulos. 2011. Insecticide resistance status of the 
codling moth Cydia pomonella (Lepidoptera: Tortricidae) from Greece. Pestic.

611 Biochem. Physiol. 100:229-238.

612

613

Wang, X., X. Li, A. Shen, and Y. Wu. 2010. Baseline susceptibility of the

614 diamondback moth (Lepidoptera: Plutellidae) to chlorantraniliprole in China. J. Econ.

615 Entomol. 103:843-848.

616

617 Wang, X., S. K. Khakame, C. Ye, Y. Yang, and Y. Wu. 2013. Characterisation of

618 field-evolved resistance to chlorantraniliprole in the diamondback moth, Plutella

$619 x y l o s t e l l a$, from China. Pest. Manage. Sci. 69:661-665.

620

621 Witzgall, P., Stelinski, L., Gut, L., Thomson, D. 2008. Codling Moth Management 622 and Chemical Ecology. Annu. Rev. Entomol. 53:503-22.

623

624 Zheng, X., X. Ren, and J. Sui. 2011. Insecticide susceptibility of Cnaphalocrocis

625 medinalis (Lepidoptera: Pyralidae) in China. J. Econ. Entomol. 104:653-658.

626

627 
Table 1. Population name, origin, year of collection, state of the insects collected ( $\mathrm{DP}=$ diapausing) and generation tested of the field codling moth populations treated with chlorantraniliprole to obtain either the probit line (Probit) or the mortality produced by the discriminant concentrations (DC). The P450 activity was calculated for the populations reported in column: P450 activity.

\begin{tabular}{|c|c|c|c|c|c|c|}
\hline Population & Country / County & $\begin{array}{c}\text { Collection } \\
\text { year }\end{array}$ & Insect collection state & $\begin{array}{c}\text { Tested } \\
\text { laboratory } \\
\text { generation }\end{array}$ & $\begin{array}{c}\text { Bioassay } \\
\text { done }\end{array}$ & $\begin{array}{c}\text { P450 } \\
\text { activity }\end{array}$ \\
\hline S-Spain & Spain / Catalunya & & & & Probit & Yes \\
\hline Bal 2-371 (SP) (07) & Spain / Catalunya & 2007 & DP larvae & $\mathrm{F} 1$ & Probit & \\
\hline Jun 14-16 (SP) (08) & Spain / Catalunya & 2008 & Non DP \& DP larvae * & $\mathrm{F} 2$ & Probit & Yes \\
\hline Cal-4 (SP) (08) & Spain / Aragón & 2008 & Non DP \& DP larvae & $\mathrm{F} 2$ & Probit & \\
\hline Torref $15-3$ (SP) (08) & Spain / Catalunya & 2008 & Non DP \& DP larvae * & $\mathrm{F} 2$ & Probit & Yes \\
\hline Torreg 11-160 (SP) (08) & Spain / Catalunya & 2008 & Non DP \& DP larvae & $\mathrm{F} 2$ & Probit & \\
\hline Bal 2-480 (SP) (08) & Spain / Catalunya & 2008 & Non DP \& DP larvae * & $\mathrm{F} 2$ & Probit & Yes \\
\hline SAS (SP) (09) & Spain / Catalunya & 2009 & DP larvae & $\mathrm{F} 2$ & Probit & \\
\hline Jun 3-63 (SP) (09) & Spain / Catalunya & 2009 & Non DP \& DP larvae * & $\mathrm{F} 1$ & Probit & Yes \\
\hline Tamarite (SP) (10) & Spain / Aragón & 2010 & Non DP \& DP larvae & $\mathrm{F} 1$ & Probit & Yes \\
\hline Riud (SP) (10) & Spain / Catalunya & 2010 & DP larvae & $\mathrm{F} 1$ & Probit & \\
\hline Torreg 11-166 (SP) (09) & Spain / Catalunya & 2008 & DP larvae * & $\mathrm{F} 2$ & DC & Yes \\
\hline La Almunia (SP) (09) & Spain /Aragón & 2009 & DP larvae & $\mathrm{F} 1$ & $\mathrm{DC}$ & \\
\hline La AlmuniaG (SP )(09) & Spain /Aragón & 2009 & DP larvae & $\mathrm{F} 2$ & DC & \\
\hline Tossal (SP) (09) & Spain / Catalunya & 2009 & Non DP \& DP larvae * & F2 & $\mathrm{DC}$ & Yes \\
\hline Malpartit (SP) (09) & Spain / Catalunya & 2009 & Non DP \& DP larvae * & $\mathrm{F} 1$ & $\mathrm{DC}$ & Yes \\
\hline Vauvert (FR) (09) & France /Languedoc-Roussillon & 2009 & DP larvae & $\mathrm{F} 2$ & DC & \\
\hline Isle SLS (FR) (09) & France / Vaucluse & 2009 & DP larvae & F2 & $\mathrm{DC}$ & \\
\hline Nedel Market (HU)(09) & Hungary / Bács-Kiskun & 2009 & DP larvae & $\mathrm{F} 2$ & DC & \\
\hline
\end{tabular}

*Adults caught in pheromone traps 
Table 1 cont. Population name, origin, year of collection, state of the insects collected (DP = diapausing) and generation tested of the field codling moth populations treated with chlorantraniliprole to obtain either the probit line (Probit) or the mortality produced by the discriminant concentrations (DC). The P450 activity was calculated for the populations reported in column P450 activity.

\begin{tabular}{|c|c|c|c|c|c|c|}
\hline Population & Country / County & $\begin{array}{c}\text { Collection } \\
\text { year }\end{array}$ & Insect collection state & $\begin{array}{c}\text { Tested } \\
\text { laboratory } \\
\text { generation }\end{array}$ & $\begin{array}{c}\text { Bioassay } \\
\text { done }\end{array}$ & $\begin{array}{c}\text { P450 } \\
\text { activity }\end{array}$ \\
\hline Aseleben (DE) (09) & Germany / Sachsen Anhalt & 2009 & DP larvae & F1 & $\mathrm{DC}$ & \\
\hline Isle SIS (FR) (10) & France / Vaucluse & 2010 & DP larvae & $\mathrm{F} 1$ & $\mathrm{DC}$ & \\
\hline Noves P (FR) (10) & France / Provence-A-C.A. & 2010 & DP larvae & $\mathrm{F} 1$ & $\mathrm{DC}$ & \\
\hline Albalate (SP) (11) & Spain /Aragón & 2011 & Non DP \& DP larvae & F2 & $\mathrm{DC}$ & Yes \\
\hline PuigvertC (SP) (11) & Spain / Catalunya & 2011 & DP larvae & $\mathrm{F} 1$ & $\mathrm{DC}$ & Yes \\
\hline PuigvertB (SP) (11) & Spain / Catalunya & 2011 & DP larvae & F1 & DC & Yes \\
\hline SAS (SP) (11) & Spain / Catalunya & 2011 & DP larvae & $\mathrm{F} 1$ & $\mathrm{DC}$ & Yes \\
\hline Noves P (FR) (11) & France / Provence-A-C.A. & 2011 & DP larvae & $\mathrm{F} 1$ & DC & \\
\hline Noves P (FR) (12) & France / Provence-A-C.A. & 2012 & DP larvae & $\mathrm{F} 1$ & DC & \\
\hline Le Thor (FR) (12) & France / Provence-A-C.A. & 2012 & DP larvae & $\mathrm{F} 1$ & $\mathrm{DC}$ & \\
\hline Isle SLS (FR) (13) & France / Vaucluse & 2013 & DP larvae & $\mathrm{F} 2$ & $\mathrm{DC}$ & \\
\hline Noves P (FR) (13) & France / Provence-A-C.A. & 2013 & DP larvae & $\mathrm{F} 2$ & DC & \\
\hline Noves P (FR) (14) & France / Provence-A-C.A. & 2014 & DP larvae & $\mathrm{F} 1$ & $\mathrm{DC}$ & \\
\hline Lumpiaque (SP) (15) & Spain /Aragón & 2015 & DP larvae & F1 & $\mathrm{DC}$ & \\
\hline Salillas (SP) (15) & Spain /Aragón & 2015 & DP larvae & F1 & $\mathrm{DC}$ & \\
\hline Le Thor (FR) (15) & France / Provence-A-C.A. & 2015 & DP larvae & $\mathrm{F} 1$ & DC & \\
\hline Meckenheim (DE) (15) & Germany & 2015 & DP larvae & F1 & DC & \\
\hline Orsingen (DE) (15) & Germany & 2015 & DP larvae & $\mathrm{F} 1$ & DC & \\
\hline Ravenna (IT) (15) & Italy & 2015 & DP larvae & $\mathrm{F} 1$ & DC & \\
\hline
\end{tabular}

*Adults caught in pheromone traps 
Table 2. Baseline susceptibility of Cydia pomonella Spanish field collected populations to chlorantraniliprole. $\mathrm{n}=$ number of individuals tested. $\mathrm{RR}-\mathrm{F}_{50}=$ resistance ratio calculated by dividing the $\mathrm{LC}_{50}$ of the strain tested by the $\mathrm{LC}_{50}$ of the most susceptible field population (Riud (SP) (10)). $\mathrm{RR}-\mathrm{L}_{50}=$ resistance ratio calculated by dividing the $\mathrm{LC}_{50}$ of the strain tested by the $\mathrm{LC}_{50}$ of the susceptible laboratory population (S-Spain). Values of the LC are $\mathrm{mg}$ a.i./kg diet. $\mathrm{LC}_{50}$ followed by the same letter are not significantly different (LC50 are considered significantly different when their CI do not overlap).

\begin{tabular}{|c|c|c|c|c|c|c|c|c|c|c|c|}
\hline \multirow{2}{*}{ Population (year) } & \multirow{2}{*}{$\mathbf{n}$} & \multicolumn{7}{|c|}{ Probit analyses parameters } & \multirow[b]{2}{*}{$\mathbf{P}^{*}$} & \multirow{2}{*}{$\begin{array}{c}\text { RR- } \\
\text { F }_{50}\end{array}$} & \multirow{2}{*}{$\begin{array}{l}\text { RR- } \\
\mathbf{L}_{50}\end{array}$} \\
\hline & & Intercept & Slope \pm SE & $\mathbf{L C}_{50}$ & CI 95\% & LC $90_{90}$ & CI 95\% & $\chi^{2}(\mathrm{dF})$ & & & \\
\hline S-Spain & 577 & 3.555 & $3.345 \pm 0.252$ & 0.087 & $0.079-0.095$ & 0.209 & $0.182-0.249$ & $0.36(4)$ & $>0.05$ & - & - \\
\hline Jun 14-16 (SP) (08) & 572 & 1.102 & $2.183 \pm 0.260$ & $0.313 b c$ & $0.220-0.426$ & 1.209 & $0.786-2.861$ & $5.09(6)$ & $>0.05$ & 1.9 & 3.6 \\
\hline Cal-4 (SP) (08) & 612 & 1.974 & $2.800 \pm 0.269$ & $0.197 \mathrm{ab}$ & $0.160-0.243$ & 0.566 & $0.427-0.867$ & $8.03(6)$ & $>0.05$ & 1.2 & 2.3 \\
\hline Torref 15-3 (SP) (08) & 400 & 0.684 & $1.954 \pm 0.260$ & $0.446 \mathrm{c}$ & $0.309-0.665$ & 2.021 & $1.173-6.365$ & $5.63(5)$ & $>0.05$ & 2.8 & 5.2 \\
\hline SAS (SP) (09) & 380 & 2.235 & $4.860 \pm 0.557$ & $0.347 \mathrm{c}$ & $0.251-0.431$ & 0.636 & $0.503-1.051$ & $37.47(4)$ & $<0.05$ & 2.2 & 4.0 \\
\hline Jun 3-63 (SP) (09) & 283 & 2.041 & $2.722 \pm 0.317$ & $0.178 \mathrm{ab}$ & $0.137-0.230$ & 0.526 & $0.383-0.849$ & $4.22(3)$ & $>0.05$ & 1.1 & 2.1 \\
\hline Tam (SP) (10) & 684 & 2.624 & $3.748 \pm 0.486$ & $0.199 \mathrm{ab}$ & $0.162-0.248$ & 0.438 & $0.332-0.749$ & $4.99(4)$ & $>0.05$ & 1.2 & 2.2 \\
\hline Riud (SP) (10) & 554 & 3.139 & $3.951 \pm 0.337$ & $0.161 \mathrm{a}$ & $0.136-0.185$ & 0.339 & $0.258-0.431$ & $11.42(5)$ & $<0.05$ & 1.0 & 1.9 \\
\hline Pooled & 4458 & 1.401 & $2.324 \pm 0.087$ & 0.250 & $0.225-0.376$ & 0.888 & $0.763-1.068$ & $186.73(50)$ & $<0.05$ & 1.6 & 2.9 \\
\hline
\end{tabular}

*The p-value $>0.05$ indicates that the observed bioassay data are not significantly different from the expected data for the probit model. 
Table 3. Susceptibility, expressed as corrected mortality (\%), of Cydia pomonella European field collected populations to discriminant concentrations of chlorantraniliprole $(0.3,1.0$ and $10.0 \mathrm{mg}$ a.i. $/ \mathrm{kg}$ diet $) . \mathrm{RR}-\mathrm{F}=$ resistance ratio for every DC was calculated by dividing the mortality of the most susceptible field population (Meckenheim (DE) (15)) by the mortality produced in every field population strain. Mean \pm SEM of the corrected mortality produced by the DCs and coefficient of variability (CV) across all the field populations were calculated. Numbers in brackets are the number of individuals tested.

\begin{tabular}{|c|c|c|c|c|c|c|c|}
\hline \multirow{2}{*}{ Population } & \multirow{2}{*}{$\begin{array}{c}\text { Control } \\
\text { mortality }(\%)\end{array}$} & \multicolumn{6}{|c|}{ Discriminant concentration (mg a.i./kg diet) } \\
\hline & & 0.3 & $\mathbf{R R}_{\mathbf{0 . 3}}$ & 1.0 & RR-F 1.0 & $\mathbf{1 0 . 0}$ & $\mathbf{R R}-\mathrm{F}_{\mathbf{1 0 . 0}}$ \\
\hline S-Spain & & $100.0(44)$ & & $100.0(47)$ & & $100.0(48)$ & \\
\hline Torreg 11-166 (SP) (08) & $4.2(48)$ & $44.3(45)$ & 2.3 & $97.8(48)$ & 1.0 & $100.0(69)$ & 1.0 \\
\hline La Almunia (SP) (09) & $0.0(50)$ & $78.6(47)$ & 1.3 & $95.7(47)$ & 1.0 & $100.0(46)$ & 1.0 \\
\hline La Almunia G (SP) (09) & $2.5(40)$ & $36.9(53)$ & 2.7 & $97.1(52)$ & 1.0 & $100.0(68)$ & 1.0 \\
\hline Tossal (SP) (09) & $6.7(45)$ & $35.4(48)$ & 2.8 & $97.7(44)$ & 1.0 & $100.0(48)$ & 1.0 \\
\hline Malpartit (SP) (09) & $2.4(42)$ & $51.0(46)$ & 2.0 & $93.6(16)$ & 1.1 & $97.8(46)$ & 1.0 \\
\hline Vauvert (FR) (09) & $0.0(48)$ & $54.2(48)$ & 1.8 & $85.3(44)$ & 1.2 & $100.0(49)$ & 1.0 \\
\hline Isle SLS (FR) (09) & $0.0(48)$ & $89.1(46)$ & 1.1 & $100.0(47)$ & 1.0 & $100.0(47)$ & 1.0 \\
\hline Nedel Market (HU) (09) & $6.1(50)$ & $93.3(48)$ & 1.1 & $96.5(51)$ & 1.0 & - & - \\
\hline Aseleben (DE) (09) & $1.6(64)$ & $90.9(59)$ & 1.1 & $100.0(60)$ & 1.0 & $100.0(64)$ & 1.0 \\
\hline Isle SIS (FR) (10) & $2.1(48)$ & $48.9(40)$ & 2.0 & $98.0(50)$ & 1.0 & $100.0(48)$ & 1.0 \\
\hline Noves P (FR) (10) & $2.0(49)$ & $69.6(47)$ & 1.4 & $100.0(48)$ & 1.0 & $100.0(45)$ & 1.0 \\
\hline Albalate (SP) (11) & $0.0(48)$ & $69.4(48)$ & 1.4 & $100.0(48)$ & 1.0 & $100.0(48)$ & 1.0 \\
\hline PuigvertC (SP) (11) & $8.3(48)$ & $81.4(47)$ & 1.2 & $93.0(47)$ & 1.1 & $100.0(48)$ & 1.0 \\
\hline PuigvertB (SP) (11) & $14.6(48)$ & $95.0(47)$ & 1.1 & $100.0(47)$ & 1.0 & $100.0(48)$ & 1.0 \\
\hline
\end{tabular}


Table 3 cont. Susceptibility, expressed as corrected mortality (\%), of Cydia pomonella European field collected populations to discriminant concentrations of chlorantraniliprole $(0.3,1.0$ and $10.0 \mathrm{mg}$ a.i. $/ \mathrm{kg}$ diet $) . \mathrm{RR}-\mathrm{F}=$ resistance ratio for every DC was calculated by dividing the mortality of the most susceptible field population (Meckenheim (DE) (15)) by the mortality produced in every field population strain. Mean \pm SEM of the corrected mortality produced by the DCs and coefficient of variability (CV) across all the field populations were calculated. Numbers in brackets are the number of individuals tested.

\begin{tabular}{|c|c|c|c|c|c|c|c|}
\hline \multirow{2}{*}{ Population } & \multirow{2}{*}{$\begin{array}{c}\text { Control } \\
\text { mortality (\%) }\end{array}$} & \multicolumn{6}{|c|}{ Discriminant concentration (mg a.i./kg diet) } \\
\hline & & 0.3 & $\mathbf{R R}-\mathbf{F}_{0.3}$ & 1.0 & RR-F 1.0 & 10.0 & RR-F 10.0 \\
\hline SAS (SP) (11) & $0.0(48)$ & $82.5(48)$ & 1.2 & $100.0(48)$ & 1.0 & $100.0(48)$ & 1.0 \\
\hline Noves P (FR) (11) & $4.7(64)$ & $79.9(47)$ & 1.3 & $100.0(63)$ & 1.0 & $100.0(46)$ & 1.0 \\
\hline Noves P (FR) (12) & $0.0(62)$ & $20.8(48)$ & 4.8 & $100.0(48)$ & 1.0 & $100.0(48)$ & 1.0 \\
\hline Le Thor (FR) (12) & $4.7(64)$ & $75.4(47)$ & 1.3 & $100.0(63)$ & 1.0 & $100.0(46)$ & 1.0 \\
\hline Isle SLS (FR) (13) & $2.1(48)$ & $38.1(61)$ & 2.6 & $67.7(79)$ & 1.5 & $98,9(95)$ & 1.0 \\
\hline Noves P (FR) (13) & $0.0(48)$ & $82.2(45)$ & 1.2 & $100.0(47)$ & 1.0 & $100.0(48)$ & 1.0 \\
\hline Noves P (FR) (14) & $0.0(48)$ & $93.3(45)$ & 1.1 & $100.0(33)$ & 1.0 & & \\
\hline Lumpiaque (SP) (15) & $4.3(82)$ & $77.8(63)$ & 1.3 & $87.2(122)$ & 1.1 & $100.0(45)$ & 1.0 \\
\hline Salillas (SP) (15) & $0.0(27)$ & $72.3(47)$ & 1.4 & $100.0(55)$ & 1.0 & $100.0(55)$ & 1.0 \\
\hline Le Thor (FR) (15) & $0.0(64)$ & $64.8(88)$ & 1.5 & $94.3(138)$ & 1.1 & & \\
\hline Meckenheim (DE)(15) & $8.3(48)$ & $100.0(53)$ & 1.0 & $100.0(45)$ & 1.0 & $100.0(48)$ & 1.0 \\
\hline Orsingen (DE) (15) & $0.0(16)$ & $93.2(44)$ & 1.1 & $100.0(45)$ & 1.0 & & \\
\hline Ravenna (IT) (15) & $4.2(96)$ & $93.7(95)$ & 1.1 & $100.0(94)$ & 1.0 & & \\
\hline Mean \pm SEM & & $70.82 \pm 4.25$ & & $96.44 \pm 1.34$ & & $99.85 \pm 0.11$ & \\
\hline $\mathrm{CV}$ & & 31.17 & & 7.21 & & 0.52 & \\
\hline
\end{tabular}


Table 4. Enzymatic P450 activity, expressed as frequency of resistant insects (\%) and mean activity $\pm \mathrm{SEM}\left(\mathrm{pg} 7 \mathrm{OH} \cdot\right.$ insect $\left.^{-1} \cdot \mathrm{min}^{-1}\right)$, of Cydia pomonella field adults. The value of the P450 threshold obtained using the S-Spain population was $23.92 \mathrm{pg} 7 \mathrm{OH} \cdot$ insect $^{-}$ ${ }^{1} \cdot \mathrm{min}^{-1}$. The frequency of resistant individuals was compared using a Pearson $\chi 2$ test ( $\mathrm{df}$ $\left.=1 ;{ }^{*} \mathrm{p}=0.05 ; * * \mathrm{p}=0.01 ; * * \mathrm{p}=0.001\right)$.

\begin{tabular}{|c|c|c|c|c|c|}
\hline Population (year) & $\mathbf{n}$ & $\begin{array}{c}\text { Resistance } \\
\text { frequency }(\%)\end{array}$ & $\begin{array}{c}\text { Mean P450 } \\
\text { activity } \pm \text { SEM }\end{array}$ & $\mathbf{L C}_{50}$ & $\begin{array}{c}\mathrm{DC}_{0.3} \\
\text { mortality } \\
(\%)\end{array}$ \\
\hline S-Spain & 223 & 10.0 & $9.64 \pm 0.74$ & 0.086 & 100.0 \\
\hline Jun 14-16 (08) & 47 & $66.0 * * *$ & $34.20 \pm 3.18$ & 0.313 & 51.8 \\
\hline Torref 15-3 (08) & 125 & $76.0 * * *$ & $54.47 \pm 2.95$ & 0.446 & 34.2 \\
\hline Bal 2-480 (08) & 8 & $100.0 * * *$ & $74.61 \pm 9.57$ & 0.408 & 49.3 \\
\hline Jun 3-63 (09) & 107 & 12.1n.s. & $10.52 \pm 0.98$ & 0.178 & 83.0 \\
\hline Torreg 11-166 (09) & 48 & $45.8 * * *$ & $31.52 \pm 4.50$ & - & 44.3 \\
\hline Tossal (09) & 41 & $85.4 * * *$ & $62.05 \pm 6.24$ & - & 35.4 \\
\hline Malpartit (09) & 82 & $91.0 * * *$ & $62.34 \pm 3.87$ & - & 51.0 \\
\hline Tam (10) & 29 & $31.0 * *$ & $20.60 \pm 2.73$ & 0.192 & 75.6 \\
\hline SAS (11) & 29 & 20.7n.s. & $16.60 \pm 2.68$ & - & 82.5 \\
\hline Albalate (11) & 23 & $27.6 * * *$ & $20.20 \pm 3.23$ & - & 69.4 \\
\hline PuigverdC (11) & 39 & $53.9 * * *$ & $30.00 \pm 3.34$ & - & 81.4 \\
\hline PuigverdB (11) & 29 & $48.3 * * *$ & $28.31 \pm 3.24$ & - & 81.4 \\
\hline
\end{tabular}


Figure 1. The frequency of resistant codling moth adults as explained by the mean enzymatic P450 activity in 11 Spanish field populations and the laboratory strain SSpain.

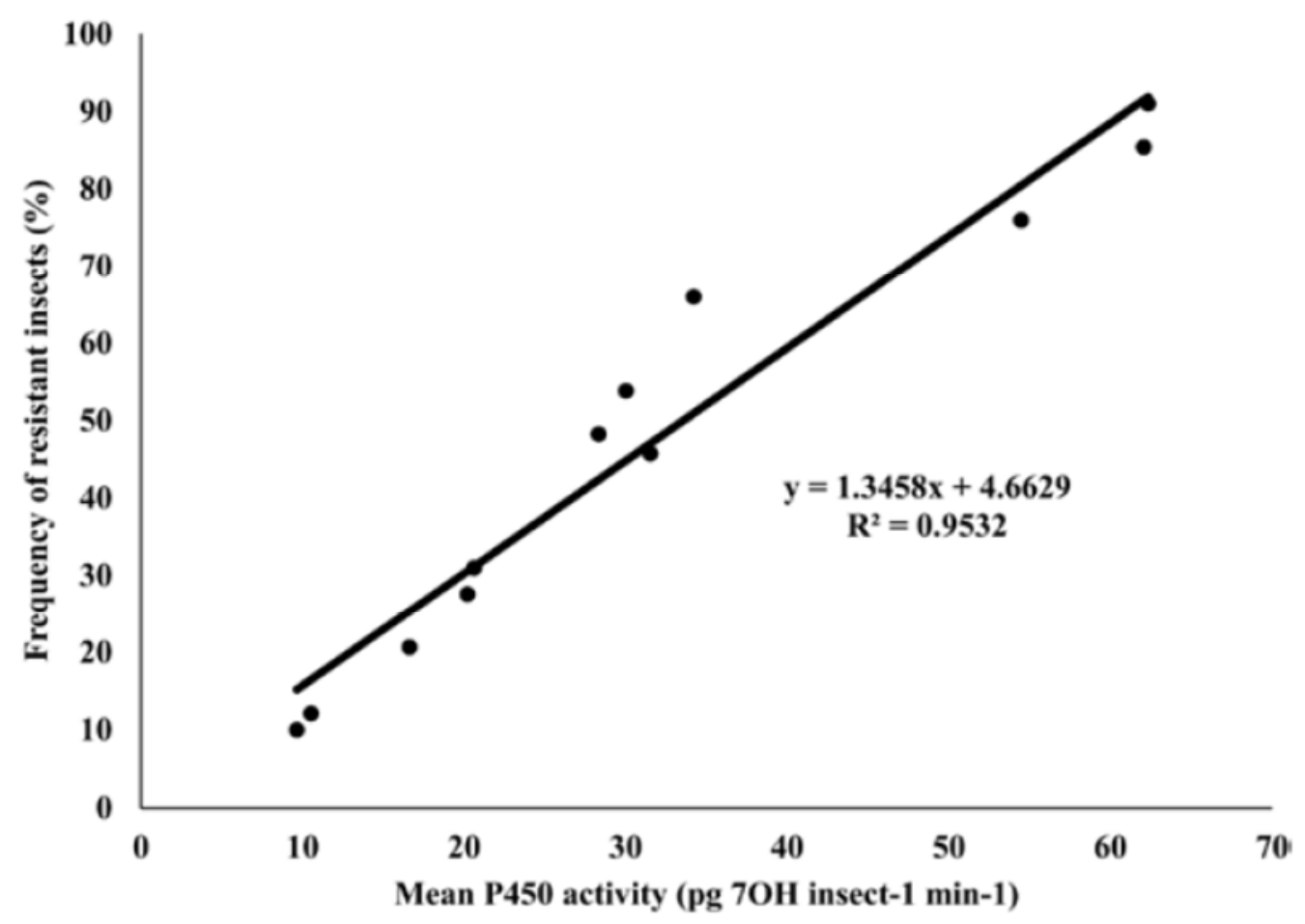


Figure 2. The $\mathrm{LC}_{50}$ of chlorantraniliprole for four Spanish field populations and the laboratory strain S-Spain as explained by the frequency of resistant codling moth adults.

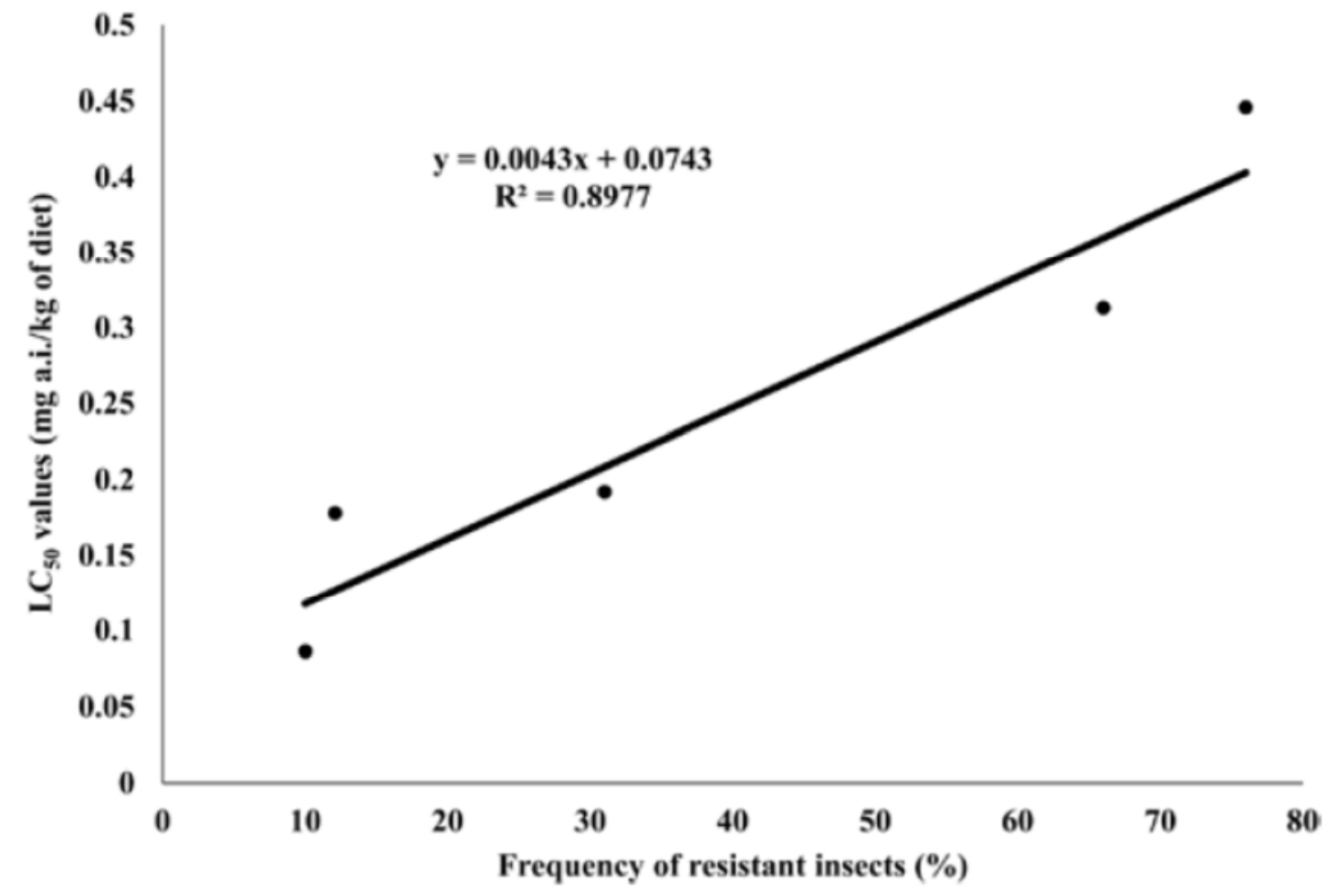


Figure 3. The mortality caused by the chlorantraniliprole $\mathrm{DC}_{0.3}$ on larvae of 11 Spanish field populations and the laboratory strain S-Spain as explained by the mean enzymatic P450 activity in adults.

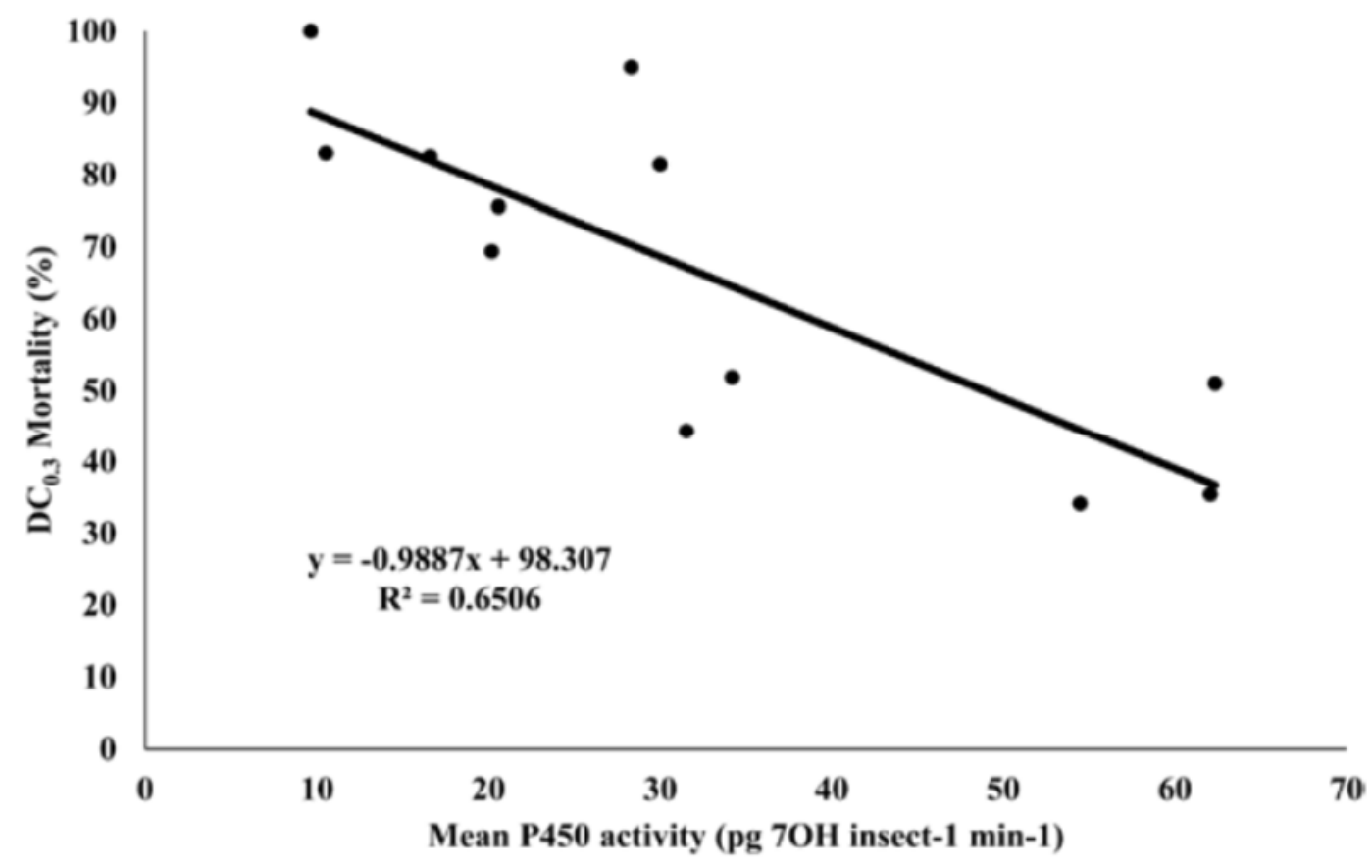

